\title{
The osteogenic factor $p$-hydroxycinnamic acid as an active component in wasabi leafstalk: role in osteoporosis prevention
}

\author{
Masayoshi Yamaguchi* \\ Department of Hematology and Medical Oncology, Emory University School of Medicine, Atlanta, GA, USA
}

\begin{abstract}
Bone mass is maintained through a balance between osteoblastic bone formation and osteoclastic bone resorption. Bone loss with aging is induced by decreasing of osteoblastic bone formation and increasing of osteoclastic bone resorption, thereby leading to osteoporosis that is widely recognized as a major public heath problem. Pharmacologic and nutritional factors may play a role in the prevention and treatment of osteoporosis. Among various food and plants tested, osteogenic factor was found to be present in the leafstalk of wasabi (Wasabi japanica MATSUM). This factor was identified to be $p$-hydroxycinnamic acid (HCA). Such an effect was not revealed in other phenolic acids including cinnamic acid, ferulic acid, caffeic acid, and 3,4-dimethoxycinnamic acid. HCA was found to stimulate osteoblastic bone formation and suppresses osteoclastic bone resorption in vitro. Oral administration of HCA was found to reveal restorative effects on bone loss induced with ovarietomy and diabetic states. Thus, HCA may have a role in the prevention and treatment of osteoporosis.
\end{abstract}

\section{Introduction}

Bone homeostasis is maintained through a delicate balance between osteoblastic bone formation and osteoclastic bone resorption, which is regulated various hormones, cytokines and bone marrow environment factors $[1,2]$. Bone mass is altered through numerous pathological processes. Osteoporosis is induced with decrease in bone mass. Postmenopausal osteoporosis, a consequence of ovarian hormone deficiency, is the archetypal osteoporotic condition in women after menopause and leads to bone destruction though complex and diverse metabolic and biochemical changes [3]. Osteoporosis is widely recognized as a major public health problem [4]. The most dramatic expression of the disease is represented by fractures of the proximal femur for which the number increases as the population ages $[3,4]$.

Diets and nutritional factors may have the potential effect to delay degenerative bone disorders such as osteoporosis. There is growing evidence that the supplementation of nutritional and food factors may have the preventive effect on bone loss that is induced in animal model of osteoporosis and in human subjects $[5,6]$. Chemical compounds in food and plants, which regulate bone homeostasis, have been to be worthy of notice in maintaining of bone health and prevention of bone loss with increasing age [7-11]. The daily consumption of fruits or vegetables may play a role in the building of optimal peak bone mass and in the preservation of decreased bone mass with aging.

Among various fruits, plants and vegetables, a novel osteogenic factor was found to present in wasabi leafstalk, and its active component was identified to be $p$-hydroxycinnamic acid (HCA) [12-15]. Cinnamic acid is present in many plant and fruits. HCA is an intermediatemetabolic substance in plants and fruits, and it is synthesized from tyrosine. HCA has been shown to stimulate osteoblastic bone formation and suppress osteoclastogenic bone resorption in vitro. HCA has been found to reveal preventive effects on bone loss with pathophysiological states including ovariectomy and diabetes state. This review has been written to outline the recent advances concerning the role of HCA in the regulation of bone homeostasis and in the prevention of osteoporosis.

\section{Anabolic effect of wasabi leafstalk extract on bone}

The effects of various foods and plants on bone tissues have been poorly understood. The effects of $20 \%$ ethanol solution extracts obtained from various foods and plants on bone calcium content were examined using mouse bone tissues in vitro. Among various food and plants (including shiitake, loquat leaf, cherry leaf, gabaron tea, green tea, muskmelon, tomato, blueberry, and wasabi leafstalk) used, the extracts of wasabi leafstalk (Wasabi japanica MATSUM) were found to reveal a potential-anabolic effect on bone calcification in mouse calvaria tissue culture in vitro [12]. The leafstalk of wasabi is shown in Figure 1.

Culture with wasabi leafstalk extract ( $10 \mu \mathrm{g} / \mathrm{ml}$ of culture medium), which wasabi leafstalk extract was obtained from a homogenate with $20 \%$ ethanol, caused a significant increase in calcium content and alkaline phosphatase activity, which participates in mineralization in the bone tissues $[12,13,16]$. The wasabi leafstalk extract-induced increase in bone calcium content was suppressed in the presence of cycloheximide, an inhibitor of protein synthesis, suggesting that the anabolic effect

Correspondence to: Masayoshi Yamaguchi, Ph.D., Department of Hematology and Medical Oncology, Emory University School of Medicine, 1365 C Clifton Road, Atlanta, GA 30322, USA, E-mail: yamamasa1155@yahoo.co.jp

Key words: Wasabi leafstalk, p-hydroxycinnamic acid, osteoblastic bone formation, osteoclastic bone resorption, osteoporosis, diabetes

Received: January 23, 2015; Accepted: February 18, 2015; Published: February 20, 2015 


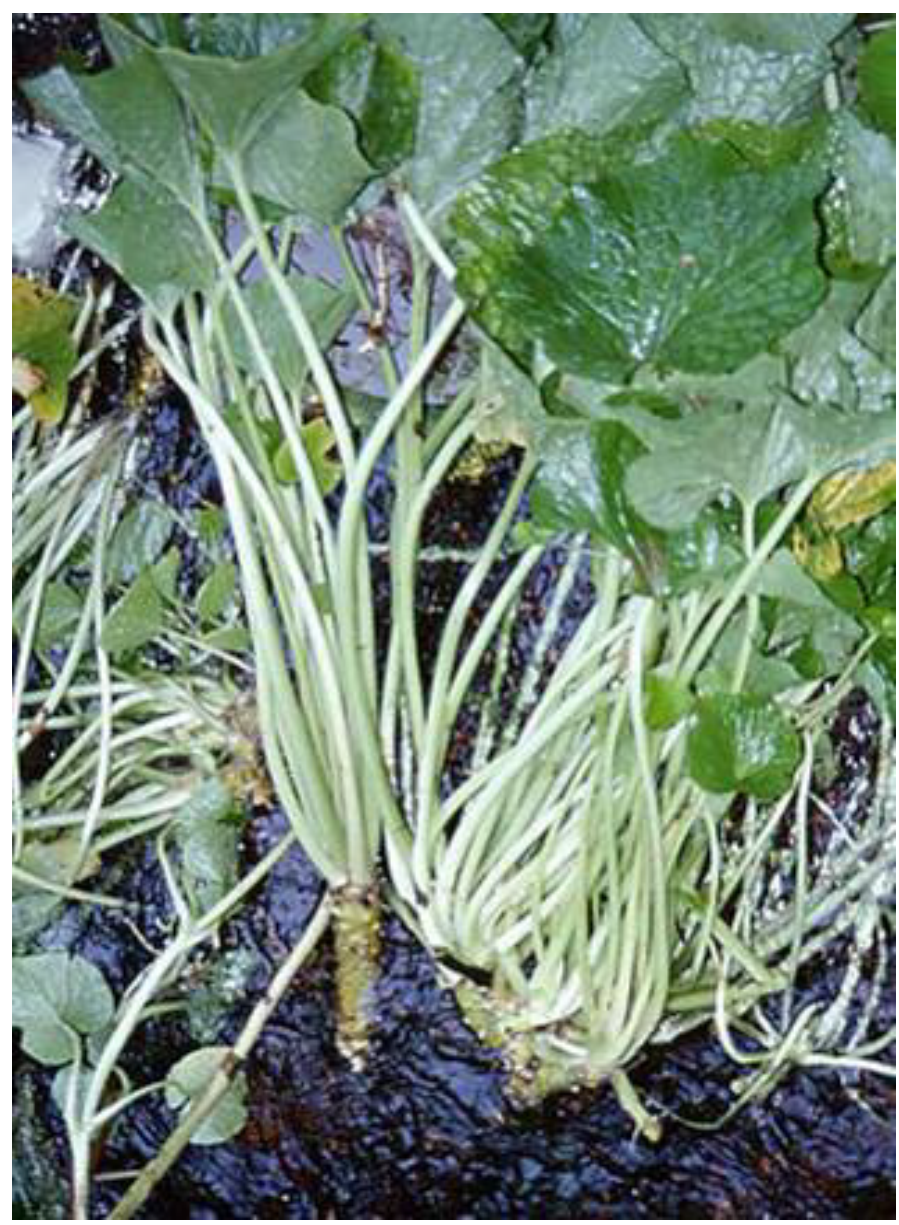

Figure 1. Leafstalk of wasabi (Wasabi japanica MATSUM).

of wasabi leafstalk extracts on bone mineralization is resulted from newly synthesized protein components $[13,16]$. Stimulatory effect of wasabi leafstalk extract on bone mineralization was compared with that of insulin, nsulin-like growth factor-I, 17 $\beta$-estradiol, and genistein [16]. Anabolic effect of $17 \beta$-estradiol $\left(10^{-10} \mathrm{M}\right)$ or insulin $\left(10^{-8}\right.$ or $10^{-}$ ${ }^{7} \mathrm{M}$ ) on bone mineralization was additively enhanced in the presence of wasabi leafstalk extract $(15 \mu \mathrm{g} / \mathrm{ml})$ [16]. Such an effect was not seen in the case of IGF-I $\left(10^{-8} \mathrm{M}\right)$. Effects of $17 \beta$-estradiol or insulin, which physiologically regulates bone formation may be enhanced by the intake of wasabi leafstalk extract. Moreover, wasabi leafstalk extract was found to reveal suppressive effects on osteoclast-like cell formation induced by parathyroid hormone (PTH), which is known to stimulate osteoclastogenesis and bone resorprtion [17], suggesting that the component inhibits bone resorption

Oral administration of wasabi leafstalk extract to young rats cased a significant increase in alkaline phosphatase activities, calcium and DNA contents in the femoral-metaphyseal tissues (trabecullar bone) in vivo [18], demonstrating the anabolic effect of wasabi leafstalk extract on bone tissues in vivo. Whether wasabi leafstalk extract reveals preventive effects on bone loss with increasing age, which induces osteoporosis, was examined in vitro and in vivo [19]. Bone metabolism in the femoral-diaphyseal and -metaphyseal tissues was deteriorated with increasing age (50 weeks old) as compared with that of young rats (4 weeks old) [20]. Presence of wasabi leafstalk extract in the culture medium caused a significant increase in alkaline phosphatase activity, calsium and DNA contents in the femoral-diaphyseal and metaphyseal tissues of aged female rats in vitro [19]. Anabolic effect of wasabi leafstalk extract on bone was resulted from newly synthesized protein components in aged rat bone tissues [19]. Moreover, oral administration of wasabi leafstalk extract was found to induce an increase in alkaline phosphatase activity, calcium and DNA contents in the femoral-diaphyseal and -metaphyseal tissues of aged female rats in vivo [19]. Oral administration of wasabi leafstalk extract did not cause any change in body weight, serum calcium or inorganic phosphorus concentrations in aged female rats, indicating that the extract may not have a toxic effect [19]. Thus, intake of wasabi leafstalk extract may reveal a preventive effect on the deterioration of bone metabolism with increasing age. Dietary wasabi leafstalk extract may play a preventive role in the progression of osteoporosis with aging.

\section{Active component of wasabi leafstalk extract}

The components of wasabi leafstalk extracts that increase bone calcium content were stable when the components were treated with heat, acidity, or alkalinization [14]. The active components of wasabi leafstalk extract were not a protein. Active component in wasabi leafstalk was purified [14]. Wasabi leafstalk extract was obtained from a homogenate with $20 \%$ ethanol. Active component, which was found in the ethanol extract, was purified upon gel filtration chromatography with a HiLoad 26/80 Superdex 30-pg column and reverse-phase chromatography on a Resource 15 RPC 3-ml column [14]. Result of ESI mass spectra for the purified active component showed that the material had a molecular weight of 158 [14]. The material with a low molecular weight of 158 was the active component in wasabi leafstalk that stimulates bone mineralization. Cinnamic acid, HCA, ferulic acid, caffeic acid, or 3,4-dimethoxycinnamic acid was found to be present in the wasabi leafstalk. When rat femoral tissues were cultured in a medium containing these phenolic acids, HCA was found to uniquely reveal potential-anabolic effects on bone mineralization in vitro [15]. The molecular weight of HCA was 164 . We judged that HCA was an active component in wasabi leafstalk that reveals bone anabolic effect. This was supported with an identification of chemical structure.

\section{HCA regulates bone homeostasis}

HCA stimulates osteoblastic bone formation: The effect of cinnamic acid and its related compounds on bone mineralization was not determined so far. Rat femoral-daiphyseal or -metaphyseal tissues were cultured for 48 hours in a medium containing cinnamic acid, HCA, ferulic acid, caffeic acid or 3,4-dimethoxycinnamic acid in vitro [15]. Culture with HCA $\left(10^{-5}\right.$ or $\left.10^{-4} \mathrm{M}\right)$ caused an increase in alkaline phosphatase activity, calcium and DNA contents in the diaphyseal and metaphyseal tissues [15]. Such effects were not seen after culture with cinnamic acid or other compounds $\left(10^{-5}\right.$ or $\left.10^{-4} \mathrm{M}\right)$. The effect of HCA was depressed in the presence of an inhibitor of protein synthesis. Thus, HCA has been found to have a unique-anabolic effect on bone metabolism, which results from newly synthesized protein components [15]. As the chemical structure of cinnamic acid and its related compounds is shown in Figure 2, HCA is hydroxylated at 4-position of cinnamic acid. This chemical form may have an anabolic effect on bone metabolism, suggesting a relationship of structure and activity of cinnamic acid.

Osteoblastic MC3T3-E1 cells were cultured for 72 hours in a minimum essential medium containing $10 \%$ fetal bovine serum (FBS) and the subconfluent cells were changed to a medium containing either vehicle or $\mathrm{HCA}\left(10^{-7}\right.$ to $\left.10^{-5} \mathrm{M}\right)$ without $\mathrm{FBS}$ in vitro [20]. Culture with HCA did not reveal a significant effect on cell proliferation of 


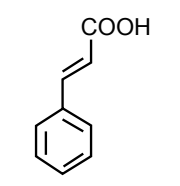<smiles>O=C(O)/C=C/c1ccc(O)cc1</smiles>

Cinnamic
p-Hydroxy-
cinnamic acid

(HCA)<smiles>COc1ccc(C=CC(=O)O)cc1O</smiles>

Ferulic<smiles>O=C(O)/C=C/c1ccc(O)c(O)c1</smiles>

\section{Caffeic acid}<smiles>COc1ccc(OC)c(/C=C/C(=O)O)c1</smiles>

\section{3,4-Dimethoxy-} cinnamic acid (DCA)

Figure 2. Chemical structures of cinnamic acid and its related compounds. The molecular weight of cinnamic acid, $p$-hydroxycinnamic acid (HCA), ferulic acid, caffeic acid, and 3,4-dimethoxycinnamic acid (DCA) is 148.2, 164.2, 194.2, 180.2, and 208.3, respectively.

osteoblastic cells [20]. Also, HCA did not induce cell death [20]. Alkaline phosphatase is involved in mineralization in osteoblastic cells [20]. Alkaline phosphatase activity in osteoblastic cells was increased after culture with HCA $\left(10^{-7}\right.$ to $\left.10^{-5} \mathrm{M}\right)$ [20], indicating that HCA stimulates cell differentiation in osteoblastic cells. The results of Alizarin red stain showed that the prolonged culture with HCA markedly stimulates mineralization in osteoblastic cells; the mineralization was stimulated after culture with HCA $\left(10^{-8}\right.$ to $\left.10^{-5} \mathrm{M}\right)$ for 7, 14, or 21 days [20], supporting the view that culture with HCA stimulates the differentiation of osteoblastic cells and mineralization in the cells. Thus, HCA was demonstrated to reveal stimulatory effects on osteoblastic differentiation and mineralization [20].

HCA suppresses osteoclastic bone resorption: Osteoclasts are generated from bone marrow stem cells. Receptor activator of the nuclear factor kappa B (NF-kB) (RANK) ligand (RANKL) plays a pivotal role in osteoclastogenesis from bone marrow cells $[17,21]$. RANKL is produced from osteoblasts in response to osteoporotic factors, such as PTH and 1,25-dihydroxyvitamin $\mathrm{D}_{3}\left(\mathrm{VD}_{3}\right)[17,21]$. RANKL acts osteoclast progenitors and stimulates osteoclast differentiation $[17,21]$. Osteoclastic cells are differentiated from bone marrow stromal cells. Osteoclastogenesis is stimulated by macrophage colony-stimulating factor (M-CSF) and RANKL in vitro $[17,21]$. A soluble fragment containing part of the extra-cellular domain of RANKL (the carboxyterminal half of the protein, amino acids 158-316) is capable of promoting osteoclastogenesis in the presence of M-CSF $[17,21]$. The receptor protein RANK for RANKL is expressed on the surface of osteoclast progenitors. The interaction of RANKL with its receptor RANK leads to the recruitment of the signaling adaptor molecules TRAFs (TNF receptor-associated factors) to the receptor complex and the activation of nuclear factor $-\mathrm{kB}(\mathrm{NF}-\mathrm{\kappa B})$ and $\mathrm{c}$-Jun N-terminal kinase (JNK) [17,21].

HCA was found to reveal suppressive effects on bone resorption induced by bone-resorbing factors in the bone tissue culture in vitro [22]. $\mathrm{PTH}$ or $\mathrm{VD}_{3}$ is known as bone-resorbing factors [17,21]. Culture with PTH caused a decrease in calcium content and an increase in the activity of tartrate-resistant acid phosphatase (TRACP), which is a marker enzyme in osteoclastic cells, in the diaphyseal or metaphyseal tissues and a corresponding elevation in medium glucose consumption and lactic acid production by the bone tissues [22]. These alterations were completely suppressed after culture with HCA $\left(10^{-5}\right.$ or $\left.10^{-4} \mathrm{M}\right)$. Thus, HCA has been shown to reveal a suppressive effect on bone resorption in the bone tissue culture in vitro [22].

Culture with HCA was also found to reveal suppressive effects on PTH-, prostaglandin $\mathrm{E}_{2}\left(\mathrm{PGE}_{2}\right)$-, or tumor necrosis factor- $\alpha$ (TNF- $\alpha$ )induced osteoclast-like cell formation from mouse bone marrow in vitro [22]. HCA did not reveal an effect on the proliferation of bone marrow cells, suggesting that the compound did not have a toxic effect on the cells [22]. Suppressive effect of HCA on osteoclast-like cell formation was remarkable at the earlier stage of the differentiation to osteoclasts in bone marrow cultures [22]. In addition, suppressive effect of HCA was also observed at the later stage of osteoclastogenesis [22]. HCA may regulate the process of differentiation from mononuclear osteoclast to osteoclast [22].

Moreover, HCA has been shown to suppress osteoclast-like cell formation induced by PTH or $\mathrm{PGE}_{2}$ [22]. Suppressive effect of HCA was partly involved in RANKL expression and/or RANKL action, which are related to the effect of PTH and $\mathrm{PGE}_{2}$. Culture with HCA suppressed RANKL plus M-CSF-induced osteoclast-like cell formation in mouse bone marrow culture in vitro [22]. Presumably, the suppressive effect of HCA is involved in RANKL expression and/or RANKL action, which

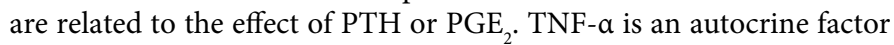
in osteoclasts, promoting their differentiation and mediating RANKLinduced osteoclastogenesis [23]. TNF- $\alpha$-induced osteoclast-like cell formation in mouse bone marrow cultures was suppressed after culture with HCA [22]. HCA may suppress osteoclastogenesis that is mediated through RANKL and TNF- $\alpha$.

$\mathrm{NF}-\kappa \mathrm{B}$ signaling is shown to suppress basal osteoblast differentiation and mineralization in MC3T3 cells and antagonizes TGF- $\beta 1$ and BMP-2 mediated MC3T3 mineralization by downregulating Smad activation [24]. Other studies found that NF$\kappa \mathrm{B}$ signaling antagonizes Smad activation in Saos2 osteosarcoma cells by a mechanism involving induction of inhibitory Smad7 [25]. TNF- $\alpha$ is an inflammatory cytokine that antagonizes bone formation in vivo and osteoblastic differentiation in vitro [24]. These effects are mediated in large measure through NF- $\mathrm{BB}$ signaling. Inflammatory levels of TNF- $\alpha$ are known to impact bone formation; however, it has been recently reported that basal TNFa levels in vivo also dramatically lower the basal bone formation rate [24]. Interestingly, HCA was found to prevent TNF- $\alpha$-induced suppression of mineralization in osteoblastic $3 \mathrm{~T} 3-\mathrm{E} 1$ cells and repressed TNF- $\alpha$-induced NF- $\mathrm{\kappa B}$ activation in the osteoblastic cells $[26,27]$. Culture with HCA was also found to suppress the differentiation of preosteoclast (RAW267.4 cells) to osteoclasts induced by RANKL through suppression of NF- $\kappa B$ activation [27].

Cellular and molecular mechanism by which HCA stimulates osteoblastic bone formation and suppresses osteoclastic bone resorption may be mediated through suppression of NF- $\kappa B$ activation. In addition, HCA was suggested to reveal suppressive effects on osteoclastogenesis that is mediated through signaling mechanim of protein kinase $\mathrm{C}$ or protein kinase $\mathrm{A}$. 
HCA stimulates osteoblastogenesis and suppresses adipogenesis in bone marrow cells: Osteoblasts and adipocytes differentiate from bone marrow mesenchymal stem cells [28]. There is an inverse relationship between differentiation of mesenchymal stem cells to osteoblasts and adipocytes. We found that culture with HCA (10$1000 \mathrm{nM}$ ) reveals a stimulatory effect on osteoblastogenesis in mouse bone marrow cells and suppresses adipogenesis in mouse bone marrow cells and mouse 3T3-L1 preadipocytes in vitro, demonstrating that HCA reveals an effect on differentiation of mesenchymal stem cells [29]. HCA was also found to suppress adipogenesis in mouse bone marrow cells and lipid production and/or stimulated lipid degradation in adipocytes in vitro [29]. Moreover, HCA revealed potent-suppressive effects on lipogenesis in the presence of insulin and did not reveal an effect on lipolysis in adipocytes independent on cell toxicity and apoptotic cell death [29]. Suppressive effects of HCA were involved in inhibition of insulin-activated MAPK/ERK signaling pathway in adipocytes [29]. Thus, HCA was found to stimulate differentiation to adipocytes from bone marrow mesenchymal stem cells.

As described above, HCA stimulates osteoblastic bone formation and suppresses osteoclastic bone resorption, thereby increasing bone mass. Moreover, HCA stimulates osteoblastogenesis and suppresses adipogenesis in bone marrow mesenchymal stem cells. Effects of HCA may be mediated through suppression of signaling pathways of NF- $\mathrm{KB}$, protein kinase $\mathrm{C}$, protein kinase $\mathrm{A}$, and insulin-activated MAPK/ERK, as shown in Figure 3.

\section{HCA prevents osteoporosis}

Anabolic effect of HCA on normal bone in vivo: The anabolic effects of HCA on the bone of rats in vivo was examined [30-32]. Rats were orally administered HCA $(10,20$, or $50 \mathrm{mg} / \mathrm{kg}$ body weight) once

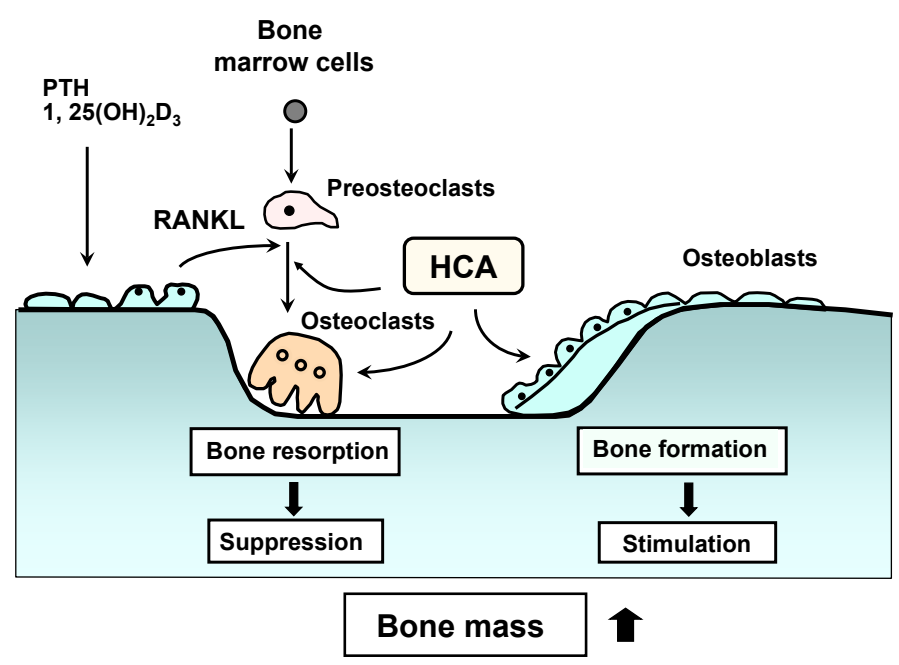

Figure 3. Involvement of $p$-hydroxycinnamic acid (HCA) in the regulation of bone cell differentiation. RANKL is produced by bone resorbing factors (PTH, $\mathrm{PGE}_{2}$ and other) in osteoblasts and binds RANK to activate osteoclastogenesis. Osteoprotegerin (OPG), a natural antagonist of RANKL, inhibits binding of RANKL to RANK. Macrophage-colony stimulating factor (M-CSF) stimulates formation of preosteoclasts from stem cells. HCA stimulates osteoblastic bone formation and suppresses osteoclastic bone resorption, thereby increasing bone mass. Osteogenic effect of HCA is mediated through suppression of NF$\kappa \mathrm{B}$ activation. Also, HCA may reveal suppressive effects on osteoclastogenesis that is mediated through signaling mechanism of protein kinase $\mathrm{C}$ or protein kinase $\mathrm{A}$. Moreover, HCA suppresses adipogenesis and stimulates osteoblastogenesis in bone marrow stem cells. Suppressive effects of HCA may relate to inhibition of insulin-activated MAPK/ERK signaling pathway in adipocytes. daily for 7 days [30]. Administration of HCA did not cause a significant change in body weight or serum calcium and inorganic phosphorus levels. Alkaline phosphatase activity, DNA and calcium contents in the diaphyseal and metaphyseal tissues were increased after the administration of HCA $(20$ or $50 \mathrm{mg} / \mathrm{kg}$ ) [30], demonstrating that the oral intake of HCA induces anabolic effects on bone mineralization in normal growing rats. The activity of TRACP, which is a marker enzyme of osteoclastic bone resorption, is enhanced by bone-resorbing factors $[17,33]$. Oral administration of HCA $(10,20$, or $50 \mathrm{mg} / \mathrm{kg})$ caused a significant decrease in TRACP activity in the femoral-diaphyseal and -metaphyseal tissues of rats [30]. This suggests that the oral administration of HCA induces a decrease in bone-resorbing activity in the femoral tissues of rats in vivo.

HCA prevents ovariectomy-induced bone loss: Preventive effect of HCA on osteoporosis was examined using ovariectomized (OVX) rats, a animal model for osteoporosis [31]. HCA $(0.25 \mathrm{or} 0.5 \mathrm{mg} / \mathrm{kg}$ body weight) was orally administered once daily for 30 days to OVX rats. The analysis using a peripheral quantitative computed tomography (pQCT) showed that OVX caused bone loss in the femoral-metaphyseal tissues [31]. This bone loss was restored after the oral administration of HCA ( 2.5 or $5 \mathrm{mg} / \mathrm{kg}$ body weight) to OVX rats [31]. Mineral content, mineral density, and polar strength strain index in the femoral-metaphyseal tissues were decreased in OVX rats [31]. These decreases were restored after the oral administration of HCA $(5 \mathrm{mg} / \mathrm{kg})$ to OVX rats [31]. The polar stress strain index is an indicator of bone strength, suggesting that the oral administration of HCA causes a functional change in the bone of OVX rats.

Thus, HCA has been shown to have preventive effects on OVXinduced bone loss of rats in vivo. HCA may stimulate osteoblastic bone formation and inhibits osteoclastic bone resorption in vivo, thereby increasing bone mass in OVX rats. The dose with HCA 2.5 or $5 \mathrm{mg} /$ $\mathrm{kg}$ body weight had a preventive effect on the decrease in alkaline phosphatase activity and calcium content or the increase in DNA content in the femoral-diaphyseal tissues of OVX rats, although the dose of HCA $5 \mathrm{mg} / \mathrm{kg}$ had great potential effects in the restoration of OVX-induced bone change [31]. This suggests that the intake of HCA less than $2.5 \mathrm{mg} / \mathrm{day} / \mathrm{kg}$ body weight has preventive effects on bone loss. The amount of intake of HCA in fruit and vegetables is unknown. However, the dietary intake of phytocomponent HCA may have a role in the prevention of bone loss with aging. HCA may have a preventive effect on bone loss with increasing age.

HCA suppresses diabetic bone loss in vivo: Bone loss is induced in the diabetic state [34]. Streptozotocin (STZ) induces type I diabetes by impairing insulin secretion from pancreatic cells. Preventive effect of HCA on bone loss induced in STZ-diabetic rats was examined in vivo [32]. Rats received a single subcutaneous administration of STZ $(60 \mathrm{mg} / \mathrm{kg}$ body weight), and the animals were orally administered HCA $(2.5,5$, or $10 \mathrm{mg} / \mathrm{kg}$ body weight $)$ once daily for 14 days [32]. STZ administration caused a decrease in body weight and a remarkable increase in serum glucose, triglyceride, and calcium levels, indicating a diabetic state [32]. These alterations were found to prevent after the administration of HCA $(2.5,5$, or $10 \mathrm{mg} / \mathrm{kg})$ [32]. Oral intake of HCA reveals improve effects on serum biochemical findings that are involved in diabetes in vivo. HCA may have a role in the prevention of diabetic states.

Serum calcium concentration was increased in STZ-diabetic rats [32]. Intestinal calcium absorption has been shown to be impaired in the diabetic state [35]. The increase in serum calcium concentration 
in STZ-diabetic rats may result from the release of calcium from the bone tissues. Calcium content in the femoral-diaphyseal and -metaphyseal tissues was found to markedly decrease in STZ-diabetic rats [32]. This decrease was prevented by the oral administration of HCA. Oral administration of HCA to type 1 diabetic rats reveled preventive effects on hypercalcemia and bone calcium loss in the diabetic state. Thus, the intake of HCA may reveal preventive effects on bone resorption in diabetic rats. Alkaline phosphatase activity in the femoral-diaphyseal and -metaphyseal tissues was found to markedly decrease in STZ-diabetic rats [32]. This decrease was prevented by the oral administration of HCA. Alkaline phosphatase participates in osteoblastic mineralization. Decreased femoral alkaline phosphatase activity may show that osteoblastic bone mineralization is impaired in the diabetic state. Intake of HCA may a stimulatory effect on osteoblastic bone formation in diabetic state. Thus, the intake of HCA has a preventive effect on bone loss in STZ-diabetic rats and has a restorative effect on serum biochemical findings in the diabetic state, suggesting that HCA reveals preventive and restorative effects on diabetic states. HCA may play a role in the prevention and treatment of osteoporosis in diabetic states.

Interestingly, HCA was demonstrated to suppress adipogenesis and stimulates osteoblastogenesis [29]. Osteoblasts and adipocytes differentiate from a common precursor cell in the bone marrow mesenchymal stem cells [28]. There is an inverse relationship between differentiation of mesenchymal stem cells to osteoblasts and adipocytes [28]. Osteoporosis has also been shown to induce with obesity, diabetes (type 1 and 2), inflammatory disease and various pathophysiological states. Type 1 and type 2 diabetes are associated with increased fracture risk [36]. Supplemental HCA may also reveal preventive and therapeutic effects on bone loss (osteoporosis) that is induced in obese type 2 diabetes.

\section{Prospect}

As mentioned above, HCA was demonstrated to have an anabolic effect on bone mass due to stimulating osteoblastic bone formation and suppressing osteoclastic bone resorption and has a restorative effect on bone loss induced in OVX and diabetic rats. This was the first time finding. Cellular and molecular mechanism by which HCA stimulates osteogenesis and suppresses osteoclastogenesis may be mediated through suppression of activation of NF- $\kappa \mathrm{B}$ of a signaling factor, which plays a pivotal role in the regulation of bone homeostasis regulated through inflammatory cytokines. Moreover, whether HCA may reveal effects on other transcription and signaling systems remains to be elucidated.

Supplemental intake of HCA may have a role in the prevention and treatment of osteoporosis. Diet and nutritional status are critical factors that influence bone development and bone loss with aging. Phytochemicals as functional food factor may play a role in delay degenerative bone disorders with aging and in treatment of osteoporosis with various pathophysiological conditions. Phytocomponent $p$-hydroxycinnamic acid (HCA) was found to reveal osteogenic effects due to stimulating osteoblastic bone formation and suppressing osteoclastic bone resorption in vitro and the preventive effects on bone loss, which is induced with ovariectomy and diabetes in vivo. HCA had a potently stimulating effect on osteogenesis as compared with that of other phenolic acids (including ferulic acid, caffeic acid, or 3,4-dimethoxycinnamic acid), indicating a relationship with chemical structure and osteogenic activity. Phytochemical HCA may be usefulness as pharmacologic tool to treat osteoporosis. HCA analog with more potential effects may be developed. Clinical studies in bone disorder are expected through further experiments.

\section{Acknowledgements}

The author was partly supported by Awards of the Sato Memorial Fundation (Japan), the Mishima Kaiun Memorial Foundation (Japan), and the Senji Miyata Foundation (Japan).

\section{References}

1. Raggatt LJ, Partridge NC (2010) Cellular and molecular mechanisms of bone remodeling. J BiolChem 285: 25103-25108. [Crossref]

2. Canalis E, McCarthy T, Centrella M (1988) Growth factors and the regulation of bone remodeling. J Clin Invest 81: 277-281. [Crossref]

3. Weitzmann MN, Pacifici R (2006) Estrogen deficiency and bone loss: an inflammatory tale. J Clin Invest 116: 1186-1194. [Crossref]

4. Johnell O, Kanis JA (2006) An estimate of the worldwide prevalence and disability associated with osteoporotic fractures. OsteoporosInt 17: 1726-1733. [Crossref]

5. Bonjour JP, Schurch MA, Rizzori R (1996) Nutritional aspects of hip fracture. Bone 18: 1395-1445. [Crossref]

6. Yamaguchi M (2002) Isoflavone and bone metabolism: Its cellular mechanism and preventive role in bone loss. J Health Sci 48: 209-222.

7. Yamaguchi M (2010) Role of nutritional zinc in the prevention of osteoporosis. Mol Cell Biochem 338: 241-254. [Crossref]

8. Yamaguchi M, Hamamoto R, Uchiyama S, Ishiyama K (2008) Effects of flavonoid on calcium content in femoral tissue culture and parathyroid hormone-stimulated osteoclastogenesis in bone marrow culture in vitro. Mol Cell Biochem 303: 83-88. [Crossref]

9. Yamaguchi M, Weitzmann MN (2011) Vitamin K2 stimulates osteoblastogenesis and

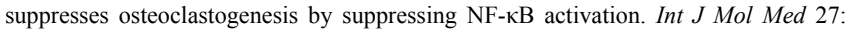
3-14. [Crossref]

10. Yamaguchi M (2008) B-Cryptoxanthin and bone metabolism: The preventive role in osteoporosis. J Health Sci 54: 356-369.

11. Yamaguchi M (2010) In: Nutritional Factors and Osteoporosis Prevention. Nova Science Publishers, Inc., New York, 2010.

12. Suzuki T, Nakayama H, Yamaguchi M (1997) Effect of wasabi leafstalk (Wasabia japonica MATSUM.) extract on bone metabolism in mouse calvaria tissue culture. Food Sci Technol Int Tokyo 3: 366-369.

13. Suzuki T, Yamaguchi M (1999) Characterization of stimulatory effect of wasabi leafstalk (Wasabia japonica MATSUM.) extract on bone calcification in mouse calvaria tissue culture. Food Sci Technol Res 5: 304-307

14. Suzuki T, Yamaguchi M (2004) Purification of active component in wasabi leafstalk (Wasabia japonica MATSUM) extract in stimulating bone calcification in vitro. $J$ Health Sci 50: 483-49

15. Lai YL, Yamaguchi M (2006) Phytocomponent p-hydroxycinnamic acid stimulates bone formation and inhibits bone resorption in rat femoral tissues in vitro. Mol Cell Biochem 292: 45-52. [Crossref]

16. Suzuki M, Yamaguchi M (2003) Stimulatory effect of wasabi leafstalk extract (Wasabia japonica MATSUM.) on bone calcification: Interaction with bone anabolic factors in mouse calvaria tissue in vitro. Food Sci Technol Res 9: 87-90.

17. Zaidi M, Blair HC, Moonga BS, Abe E, Huang CL (2003) Osteoclastogenesis, bone resorption, and osteoclast-based therapeutics. J Bone Miner Res 18: 599-609. [Crossref]

18. Suzuki T, Yamaguchi M (1999) Anabolic effect of wasabi leafstalk (Wasabia japonica MATSUM.) extract on bone metabolism in rats. Food Sci Technol Res 5: 61-63

19. Yamaguchi M, Ma ZJ, Suzuki T (2003) Anabolic effect of wasabi leafstalk (Wasabia japonica MATSUM.) extract on bone components in the femoral-diaphyseal and -metaphyseal tissues of aged female rats in vitro and in vivo. J Health Sci 49: 123-128

20. Yamaguchi M, Lai YL, Uchiyama S, Nakagawa T (2008) Phytocomponent p-hydroxycinnamic acid stimulates mineralization in osteoblastic MC3T3-E1 cells. Int J Mol Med 22: 287-291. [Crossref] 
21. Zaidi M, Blair HC, Moonga BS, Abe E, Huang CL (2003) Osteoclastogenesis, bone resorption, and osteoclast-based therapeutics. J Bone Miner Res 18: 599-609. [Crossref]

22. Lai YL, Yamaguchi M (2007) Phytocomponent p-hydroxycinnamic acid inhibits osteoclast-like cell formation in mouse bone marrow cultures. Int J Mol Med 19: 123128. [Crossref]

23. Nanes MS1 (2003) Tumor necrosis factor-alpha: molecular and cellular mechanisms in skeletal pathology. Gene 321: 1-15. [Crossref]

24. Li Y, Li A, Strait K, Zhang H, Nanes MS, et al. (2007) Endogenous TNF $\alpha$ lowers maximum peak bone mass and inhibits osteoblastic Smad activation through NF- $\mathrm{BB} . J$ Bone Miner Res 22: 646-655. [Crossref]

25. Eliseev RA, Schwarz EM, Zuscik MJ, O'Keefe RJ, Drissi H, et al. (2006) Smad7 mediates inhibition of Saos2 osteosarcoma cell differentiation by NFкB. Exp Cell Res 312: 40-50. [Crossref]

26. Yamaguchi M, Weitzmann MN (2009) The bone anabolic carotenoids p-hydroxycinnamic acid and $\beta$-cryptoxanthin antagonize NF- $\kappa$ B activation in MC3T3 preosteoblasts. Mol Med Rep 2: 641-644. [Crossref]

27. Yamaguchi M, Weitzmann MN (2012) The bone anabolic carotenoid p-hydroxycinnamic acid promotes osteoblast mineralization and suppresses osteoclast differentiation by antagonizing NF- $\kappa \mathrm{B}$ activation. Int J Mol Med 30: 708-71. [Crossref]

28. Gharibi B, Abraham AA, Ham J, Evans BA (2011) Adenosine receptor subtype expression and activation influence the differentiation of mesenchymal stem cells to osteoblasts and adipocytes. J Bone Miner Res 26: 2112-2124. [Crossref]
29. Yamaguchi M1, Baile CA, Zhu S, Shoji M (2013) Bioactive flavonoid p-hydroxycinnamic acid stimulates osteoblastogenesis and suppresses adipogenesis in bone marrow culture. Cell Tissue Res 354: 743-750. [Crossref]

30. Lai YL, Yamaguchi M (2006) Oral administration of phytocomponent p-hydroxycinnamic acid has anabolic effects on bone calcification in femoral tissues of rats in vivo. J Health Sci 52: 308-312.

31. Yamaguchi M, Lai YL, Uchiyama S, Nakagawa T (2008) Oral administration of phytocomponent p-hydroxycinnamic acid prevents bone loss in ovariectomized rats. Mol Cell Biochem 311: 31-36. [Crossref]

32. Yamaguchi M, Uchiyama S, Lai YL (2007) Oral administration of phytocomponent p-hydroxycinnamic acid has a preventive effect on bone loss in streptozotocin-induced diabetic rats. Int J Mol Med 19: 803-807. [Crossref]

33. Minkin C (1982) Bone acid phosphatase: tartrate-resistant acid phosphatase as a marker of osteoclast function. Calcif Tissue Int 34: 285-290. [Crossref]

34. Shires R, Teitelbaum SL, Bergfeld MA, Fallon MD, Slatopolsky E, et al. (1981) The effect of streptozotocin-induced chronic diabetes mellitus on bone and mineral homeostasis in the rat. J Lab Clin Med 97: 231-240. [Crossref]

35. Nyomba BL, verhaeghe J, thomasser M, Lissens W, Bouillon R (1980) Bone minera homeostasis in spontaneously diabetic BB rats. I. Abnormal vitamin D metabolism and impaired active intestinal calcium absorption. Endocrinology 124: 565-572

36. Nielson CM, Srikanth P, Orwoll ES (2012) Obesity and fracture in men and women: an epidemiologic perspective. J Bone Miner Res 27: 1-10. [Crossref]

Copyright: $\odot 2015$ Yamaguchi M. This is an open-access article distributed under the terms of the Creative Commons Attribution License, which permits unrestricted use, distribution, and reproduction in any medium, provided the original author and source are credited. 